Research Article

\title{
New Mortar Mixes with Chemically Depolymerized Waste PET Aggregates
}

\author{
Dora Foti (i) and Michela Lerna \\ Department of Civil Engineering and Architecture, Polytechnic of Bari, Bari, Italy \\ Correspondence should be addressed to Dora Foti; d.foti@poliba.it
}

Received 28 May 2020; Revised 15 November 2020; Accepted 3 December 2020; Published 12 December 2020

Academic Editor: Norbert Randl

Copyright (c) 2020 Dora Foti and Michela Lerna. This is an open access article distributed under the Creative Commons Attribution License, which permits unrestricted use, distribution, and reproduction in any medium, provided the original work is properly cited.

\begin{abstract}
Nanoparticles are used in innovative mortars in order to improve their engineering properties. In this paper, recycled PET (polyethylene terephthalate) nanoparticles were used as a substitute for sand in mortars. PET aggregates were obtained cutting water bottles wastes into many small sized pieces and the plastic fibres were treated through chemical depolymerization process. Mortars with different percentages of PET were tested to determine their physical and mechanical (flexural and compressive strength) properties. Specific attention is given to the heat-transfer capacity of the cement pastes investigated. The results of the mechanical tests showed a reduction of the flexural and compressive strength values when the amount of PET nanoparticles increase. The thermal conductivity tests showed that chemically depolymerized PET nanoparticles derived from plastic wastes reduced the heat conduction capacity of the mortar. Therefore, the innovative mortars here tested can be considered for thermal insulation applications in the construction field with the advantage of recycling waste PET.
\end{abstract}

\section{Introduction}

Polyethylene terephthalate or PET is defined as a polyester resin which results from the combination of terephthalic acid and ethylene glycol or dimethyl terephthalate and ethylene glycol [1]. Furthermore, it accounts for around $(18 \%)$ of all polymers, which are produced worldwide; over $60 \%$ of its production can be used for synthetic fibres and bottles, which form approximately $30 \%$ of global PET demand [2]. It is generally used for various applications such as bottles, mouldings, fibres, and sheets due to its excellent tensile and impact strength, clarity, chemical resistance, thermal stability, and process ability. It is commonly agreed that PET, which differs from natural polymers, is a nondegradable polymer in the natural environment and becomes a pollutant when it is discarded after use. Therefore, it has been noticed that recycling the discarded PET polymer is one of the most important approaches to protect the environment and reduce the consumption of resources at the same time [3].

Nowadays, in fact, the recycling rate of PET bottles is much lower than the sales of virgin PET production for common uses. This gap is dramatically increasing, pushing towards finding a solution to this problem and a higher recycle of PET. As a consequence, the reuse of waste PET bottles is stirring particular interest. With the aim to reduce the waste and take profit from this material in the last two decades, many authors investigated the uses of PET in concrete. This field has been investigated in several different ways, focusing on different possible utilization of this material [4].

In recent decades, with the aim of giving the conglomerate a better behavior in terms of mechanical characteristics, it was attempted to add in its mixture fibres and aggregates of various types $[5,6]$. A possible application is to utilize waste PET fibres as reinforcement for concrete to 
improve its tensile strength [7-12]. Concrete, as it is known, is a material with good compressive strength but low tensile strength. This reduced tensile strength is partly due to the presence of micro- and macrocracks caused by shrinkage of the concrete. These cracks, moreover, represent a factor in the aggression of steel bars in reinforced concrete elements provoking a fast oxidation of the bars and the degradation of the structure accompanied by a reduction of its tensile strength.

Some preliminary studies on the utilization of fibres obtained from PET bottles to improve the mechanical behaviour of concrete can be found in Silva et al. [13]. The good results of this experimental study pushed the research towards the utilization of this kind of fibres. However, what makes PET so important, among the plastics used as reinforcement for concrete, is its recyclability together with the great abundance of postconsumer waste in the form of bottles. The presence of fibres improves the tensile behaviour of concrete thanks to the sewing effect that they have on the cracks [14]. Their action, in fact, is more effective in the postcracking phase, preventing and reducing the propagation of cracks. Concretes with a higher ductility and a reduced shrinkage cracking are obtained. Ductility is evidenced by a large deformation associated with the fibre elongation at break.

From the point of view of recycling waste to be added in concrete the use of waste PET bottles in concretes is not as common as scrap rubbers since slitting, shredding, and retreating processes are relatively more complex and costly [15].

Mechanical recycling is a current industrial technique for the recovery of waste polymers, but another available pathway for recycling of polymers consists in the chemical processing. This type of recycling has a high potential for heterogeneous and contaminated plastic waste material if the separation is neither economical nor completely technically feasible $[16,17]$. Chemical recycling routes can be roughly divided into thermochemical and catalytic conversion processes. Chemical recycling of PET can completely depolymerize it into its monomers terephthalic acid, dimethyl terephthalate, bis(hydroxylethylene) terephthalate, and ethylene glycol (EG). The depolymerization is the reverse reaction of the polymer formation route. There are different depolymerization routes such as methanolysis, glycolysis, hydrolysis, ammonolysis, aminolysis, and hydrogenation, depending on the chemical agent used for the PET chain scission. Glycolysis is the simplest and oldest method of PET depolymerization, converting the polymers into smaller molecules, which can be subsequently seen as sustainable through a closed system glycolysis process.

The plastic waste material can often be heterogeneous and contaminated so as to make the mechanical production of PET aggregates difficult. Furthermore, the separation process is not economical and in many cases not entirely technically feasible. Consequently, the chemical recycling process has a high potential in PET-waste recycling. In the chemical process, the PET bottles do not need to be purified as instead provided for the mechanical one. Chemical recycling by glycolysis is a suitable tool and this should reduce the cost of the recycled pet base. The polimeric mortar applications thus helps to reduce costs and provides long-term disposal of PET waste, an important consideration in recycling applications.

In this paper, the authors have studied the possibility to adopt a chemical approach to depolymerize PET (DPET) in order to use it in the cement paste as a substitute for, or in addition to, sand. In particular, the effect of additive degraded PET on the properties of cement paste has been analysed. Consequently, the effect on the mechanical and thermal properties of modified paste has been studied, finding an improvement especially in terms of heat-transfer; finally, the optimum percentage of plastic waste (PET) by comparing the conventional and modified material has been determined.

\section{Substitution of Aggregates}

In the last decade, more attention has been paid, to the use of aggregates made from PET bottles as a partial replacement of the aggregate in the concrete mix. Choi et al. [18] published an in-depth research on the subject that analysed the substitution of fine aggregate with PET bottles lightweight aggregate. The tests, carried out on concrete specimens prepared with varying percentages of aggregate replacement $(0 \%, 25 \%, 50 \%$, and $75 \%$ by volume of inert), regarded numerous properties of the concrete such as the density, the failure, the workability, the compressive and tensile strengths, and the modulus of elasticity, thereby creating an almost complete framework on this subject. The results showed first a decrease of the specific weight of concrete as the content of PET increases. The influence of the substitution of aggregates on the workability of concrete was also studied; it was found to grow with the fraction of inert replaced, also thanks to the spherical shape of the aggregate in PET. With regard to the compressive and tensile strengths, instead, a reduction was pointed out in correspondence of the increased proportion of the replaced aggregate.

Further studies were carried out on this topic in the following years. Among these, it is worth citing the results obtained in 2007 by Marzouk [19], who showed that the partial or complete substitution of sand with PET in concrete composites does not affect either the compressive nor the tensile strengths of concrete if the level of substitution is below $50 \%$ of the volume. PET aggregates, however, should not have an equivalent diameter lower than $5 \mathrm{~mm}$, as it does not significantly influence the compressive and tensile strength of the concrete. These results represent a significant incentive to the innovative use of PET, since they confirmed the undeniable economic benefits regarding the possibility of using waste material readily available and the environmental aspects, which involve the possibility to reduce the waste.

The same results are found in [20] where $5 \%$ by weight of siliceous sand was substituted with PET in the concrete mix. WPET aggregates were manufactured from waste PET bottles and, through a grinding process, these granules pass from a thickness of $1-1.5 \mathrm{~mm}$ to the size of $0.1-5 \mathrm{~mm}$. Irrelevant differences were detected in the compressive and 
tensile strengths in case of mixes containing Waste PET (WPET) at low w/c ratio (0.45). The differences became slightly more significant by increasing the $\mathrm{w} / \mathrm{c}$ ratio (up to 0.55 ) because the interface between WPET and the hydrated cement Portland presented a higher porosity. In this case, it was detected that small percentages of fine aggregates (PET) do not affect the water absorption. As a result of this study, when WPET is used as a partial substitute for fine aggregates in a reference concrete, there is an increase in the toughness and ductility, the same values of workability, and a shrinkage influenced by the higher ductility but still acceptable for the structural elements.

In other research studies, instead, (i.e., Hannawi et al. [21]) a decrease in compressive strength is observed with the use of PET (particle size $\leq 10 \mathrm{~mm}$ ) and polycarbonate (particle size $\leq 5 \mathrm{~mm}$ ) waste aggregates as replacement in volume of sand. Probably it can be attributed to the poor bond between the matrix and plastic aggregates, but the specimens tested were able to carry a load for a few minutes after failure without full disintegration, showing also a higher ductility. This trend seems to be more obvious as the percentage of plastic aggregates increases. Otherwise, the flexural strength values remain almost unchanged when the sand volume substituted with aggregates varies in a range of about $0-20 \%$. Additionally, a significant improvement of the postpeak flexural behaviour is observed. The calculated flexural toughness factors increase significantly by increasing the volume fraction of PET and polycarbonate aggregates because also the energy absorbing capacity increases, a fundamental characteristic in case of dynamic or impact forces (in fact there is a decrease of the elastic modulus). In addition, the good sewing effect of PET and polycarbonate fibres has been experimentally demonstrated in the postcracking phase of concrete when included in the concrete mix as aggregates.

Recently, a study similar to [21] has been developed in [22] where PET has been obtained from waste bottles subjected to a grinding process to obtain PET particles used as fine aggregates in the concrete. In this case, lower percentages of PET than in [21] have been utilized as a substitute for sand $(5 \%, 10 \%$, and $15 \%)$ but the results indicate a lower density. For these percentages of PET, a lower workability has been detected, together with a lower modulus of elasticity and splitting tensile strength with respect to a conventional concrete. The compressive and flexural strengths show an ascending trend at the initial stages; however, they tend to decrease in the second stage. Finally, to investigate the structure of the concrete containing PET particles, ultrasonic pulse tests have been performed and a porous structure has been observed. As demonstrated by experimental results in a further study, the mechanical properties of the concrete depend on the PET particle size and its concentration [23]. Lower sizes and concentrations of PET particles create less space in the concrete, and, consequently, the compressive strength and the compression strain increase, while Young's modulus decreases when the size of PET particles used is increased. This means that deformations tend to be higher, but the maximum stresses reduce in magnitude.
In order to use the recycled PET nanoparticles in addition to or a substitute for fine aggregates (i.e., sand) in the cement paste, the chemically polymerization process of PET can be a valuable tool to reuse the PET wastes. PET is considered as a polyester with functional ester groups that are cleaved by reagents, like acids, bases or water (hydrolysis), alcohols (alcoholysis), amines (aminolysis), ammonia (ammonolysis), and glycols (glycolysis). Previous studies have shown that it is possible to use plastic waste in concretes, mortars, or bituminous conglomerates as a binder with the aim to remove the PET waste by means of mixing it directly into the mixtures $[24,25]$. Most of the studies carried out for the depolymerization of PET have discussed the role of various types of glycols and metal acetates to be used as catalyst in the process [26-28].

The main depolymerization processes that have reached commercial maturity up to now are glycolysis. Specifically, the glycolysis reaction is the molecular degradation of PET polymer by glycol, in the presence of trans-esterification catalysts, basically by using ethylene glycol as solvent. The ester linkages of PET polymer are broken and replaced by hydroxyls terminals to give bis (2-hydroxyethyl terephthalate) (BHET), which is the raw material for producing PET, according to the following reaction scheme [29]:

$$
\mathrm{PET}_{n}+(n-1) \mathrm{EG} \rightleftarrows n \mathrm{BHET}
$$

Glycolysis of PET is the most frequent process by using metal acetates ( $\mathrm{Zn}, \mathrm{Co}, \mathrm{Pb}$, and $\mathrm{Mn}$ ) as catalysts [30].

Studies on the kinetics of PET glycolysis have revealed that glycolysis without using a catalyst seems to be very slow and a complete depolymerization of PET to BHET cannot be achieved. In addition, it yields an end-product which has a significant number of other oligomers in addition to the BHET monomer. These results face difficulty in recovering the BHET monomer when it is the aimed product. The current interest in the depolymerization of PET by glycolysis to recover bis-hydroxyethyl terephthalate (BHET) monomer has led to studies of glycolysis catalysts. Therefore, the efforts of recent research is directed towards duplicating the rate and BHET monomer yielded through the development of highly efficient catalysts and other techniques, in addition to optimizing the reaction conditions (such as time, temperature, PET/catalyst ratio, and PET/EG ratio) [31, 32]. It has been concluded that zinc acetate is the most suitable glycolysis catalyst of the four metal acetates (lead, zinc, cobalt, and manganese) under a pressure of $1 \mathrm{~atm}$ [33].

In the present paper, the influence of using processed PET waste particles as a part of fine aggregates on the mechanical and physical properties of cementitious paste is investigated. In particular, the amount to be substituted is determined as weight percentage of the sand. In the following, the process of PET particles production is described and illustrated.

\section{Materials and Test Methods}

3.1. Materials and Samples Preparation. In this study, the depolymerized PET obtained by chemical degradation of plastic water bottles is added as a modifier of cement paste to 
evaluate the recycled effect on mechanical behaviour. Ordinary Portland cement type CEM I-52.5R was used throughout the current experimental campaign of preparation of the specimens. The chemical composition of the cement employed is presented in Table 1.

In the first phase, PET water bottles were cut into many small sized pieces. Such plastic particles with diameter equal to $2 \mathrm{~mm}$ were employed in the PET depolymerization process through the glycolysis reaction. The $\mathrm{C}_{2} \mathrm{H}_{6} \mathrm{O}_{2}$ Ethylene Glycol (EG) solvent and the catalyst consists of $\mathrm{TiO}_{2}$ zinc-dioxide particles were added to allow the reaction activation. In the mixture, the EG: PET molar ratio was equal to $4: 1$ with $0.5 \%$ catalyst based on the weight of PET. In PET chemical recycling phase, the mixture was heat-treated at $190 \mathrm{o}$ C for five hours until the mixture came in the resin state [34]. Heat treatment was involved in the complete condensation in close system through the use of glass condenser using water as a cooler (Figure 1(a)). The unreacted (EG) solution was separated in the form of depolymerized polyethylene terephthalate (DPET) as shown in Figure 1(b). After a liquid separation, the solid component was ground and reduced to fine powder with diameter $30 \mathrm{~nm}$.

In the second phase, different cement pastes were produced depending on the manufacturing of the specimens. The cement mixtures were obtained to replace a part of sand with DPET particles. The nanoparticles were mixed with cement in a dry condition, and the dry mixtures were sieved several times for a proper dispersion of the nanoparticles. The materials were mixed in a planetary mixer according to the UNI-EN 196 recommendations [35]. The water-cement ratio $(\mathrm{W} / \mathrm{C})$ used was set to 0.45 .

Seven cement pastes were prepared using normalized sand (according to UNI-EN 196-1-2006 [35]) and unnormalized sand with particle size from values of 0.5 to $2 \mathrm{~mm}$. The samples of the DPET mixtures were prepared to measure the additional effect of DPET to the mixture and to using six different amounts added to the content of cement (Table 2).

Three samples $(40 \mathrm{~mm} \times 40 \mathrm{~mm} \times 160 \mathrm{~mm})$ were prepared for each proportion to determine the unit weight, flow, mechanical characteristic (compressive and flexural strength), and thermic properties.

\subsection{Test Methods}

3.2.1. Thermal Conductivity. The thermal conductivity and the specific heat capacity were measured using the multifunctional commercial device, ISOMET 2104. Such instrument is equipped with various types of optional probes, for example, needle probes for porous, fibrous, or soft materials, and surface probes for hard materials. The measurement of the thermal properties of the material is based on the analysis of temperature response to heat flow impulses. The surface of sample to test is put in direct thermal contact with the heat flow induced by a resistor. The thermal data in this research were acquired measuring the moisture content constantly (Figure 2).

3.2.2. Flexural Strength. For each investigated mortar described in Table 2, three specimens were casted according to EN 196-1 [34]. All $40 \times 40 \times 160 \mathrm{~mm}$ prismatic specimens
TABle 1: Chemical composition of cement.

\begin{tabular}{lc}
\hline Oxides & Content (\%) \\
\hline $\mathrm{SiO}_{2}$ & 20.3 \\
$\mathrm{Al}_{2} \mathrm{O}_{3}$ & 4.4 \\
$\mathrm{Fe}_{2} \mathrm{O}_{3}$ & 2.6 \\
$\mathrm{CaO}$ & 62.5 \\
$\mathrm{MgO}$ & 2.5 \\
$\mathrm{SO}_{3}$ & 2.1 \\
$\mathrm{LOI}$ & 1.0 \\
\hline
\end{tabular}

(Figure 3) were stored at $20 \mathrm{C}(90 \% \mathrm{RH})$. As suggested by EN 196-1 https://www.sciencedirect.com/science/article/pii/ S0950061816317111?casa_token=4vjs3FIZOn4AAAAA:n0E oE21cF3wBGXgIc5w5w8sQIA0bzi7Dmdq5Rp6utBk710KLP JeqPbKAUf28HaiFEoEZh337fg [35], three point bending tests were carried out after 28 days to assess the flexural strength. The external load $P$ was applied through an Instrom L.T.D. loading machine, having a loading capacity of $50 \mathrm{kN}$. Tests were performed by driving the displacement of the loading cell, whose stroke moved at a velocity of $0.5 \mathrm{~mm} / \mathrm{min}$. Both the applied load $P$ and the midspan deflection $\delta$ of the beam were recorded during the tests, until the complete failure of the specimen (Figure 4).

The flexural strength was determined by the following according to [35]:

$$
R_{\mathrm{f}}=\frac{1.5 * P * l}{b^{3}},
$$

where $R_{\mathrm{f}}$ is the flexural strength $\left(\mathrm{N} / \mathrm{mm}^{2}\right) ; P$ is the load applied to the middle of the prism at the first crack, in Newtons; $b$ is the side of the square section of the prism, in millimetres; $l$ is the distance between the supports, in millimetres.

3.2.3. Compressive Strength. Compressive strength tests of the cement paste samples were carried out at 28 days after casting. The cubic specimens were obtained by the prismatic samples after being tested for bending. The flat surfaces of the cubic specimens were polished and smoothed in order to eliminate the unevenness. Three samples were tested for each paste. The load was applied perpendicularly and continuously on the specimen by using a hydraulic testing compression machine with a maximum load of $150 \mathrm{kN}$. The compressive strength was determined according to [35] (Figure 5).

The compressive strength of the specimen was calculated by dividing the maximum load carried by the specimen during the test by the average cross-sectional area of the specimen as shown in the following in accordance with [35]:

$$
R_{\mathrm{c}}=\frac{F_{\mathrm{c}}}{A},
$$

where $R_{\mathrm{c}}$ is the compressive strength, in $\mathrm{N} / \mathrm{mm}^{2} ; F_{\mathrm{c}}$ is the maximum load at fracture in Newtons; $A$ is the area of the prism face in millimetres $(40 \times 40)$.

\section{Results and Discussion}

4.1. Flow Value. To evaluate the fluidity of the cement pastes, a slump test was conducted on the cementitious mix prepared at the laboratory by using the slump cone or Abrams 


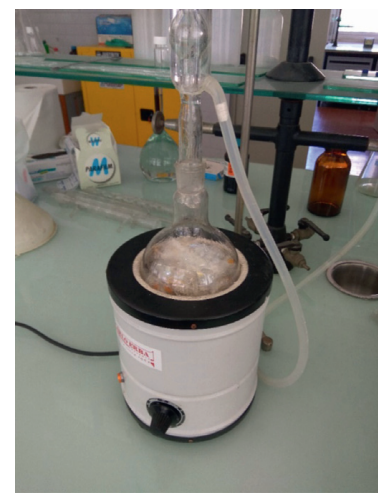

(a)

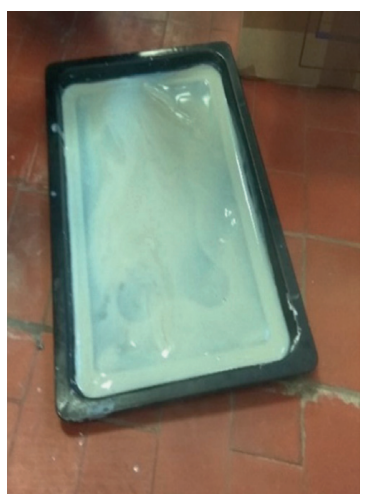

(b)

FIGURE 1: (a) Close system of chemical recycling step; (b) depolymerization of polyethylene terephthalate (DPET) after a liquid separation.

TABle 2: Mixture typologies with the sand type used and the weight replacement of sand by DPET.

\begin{tabular}{|c|c|c|c|c|c|c|}
\hline Cement paste & Sand type & Sand $(\mathrm{g})$ & DPET (g) & Sand $(\%)$ & DPET (\%) & Specific weight $\rho\left(\mathrm{kg} / \mathrm{m}^{3}\right)$ \\
\hline 1 & Normalized & 500 & - & 100 & - & 2100 \\
\hline 2 & Normalized & 350 & 150 & 70 & 30 & 1950 \\
\hline 3 & Unnormalized & 500 & - & 100 & - & 1960 \\
\hline 4 & Unnormalized & 400 & 100 & 80 & 20 & 1812 \\
\hline 5 & Unnormalized & 300 & 200 & 60 & 40 & 1636 \\
\hline 6 & Unnormalized & 200 & 300 & 40 & 60 & 1494 \\
\hline 7 & Unnormalized & 100 & 400 & 20 & 80 & 1451 \\
\hline
\end{tabular}

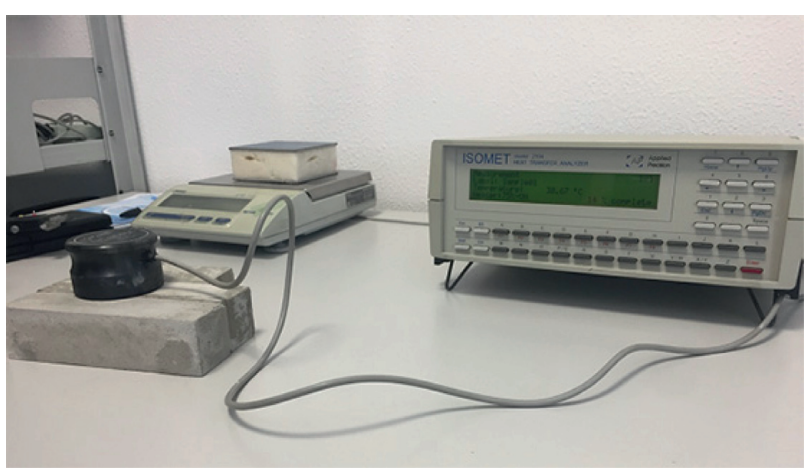

FIgURe 2: Conductivity test device.

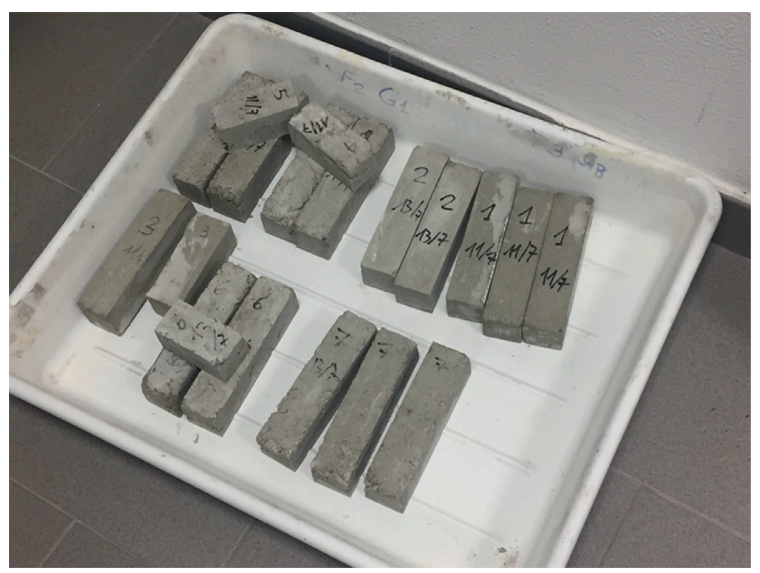

Figure 3: DPET-prismatic samples tested to flexural load.

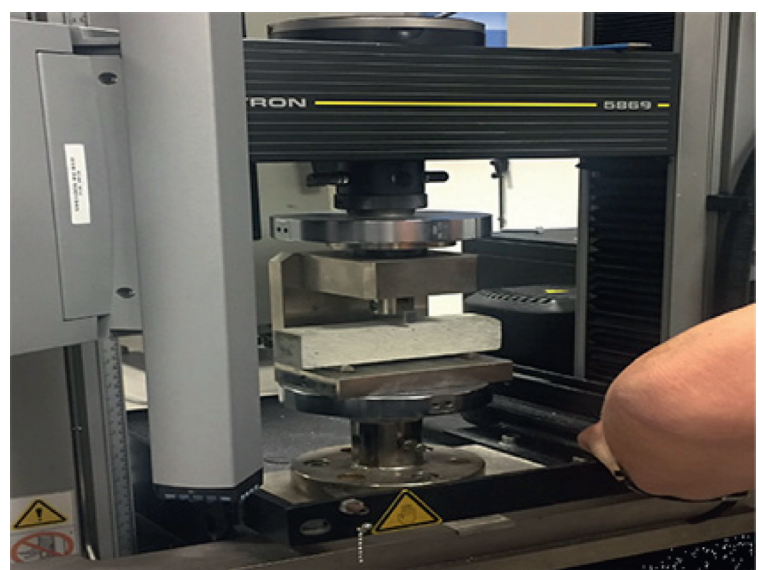

Figure 4: Flexural test on prismatic sample.

cone, which was filled with the prepared mortar mix in three stages. The slump was thus determined by measuring the distance from the top of the subsided cement paste to the level of the top of the slump cone and was recorded in terms of millimetres. In Figure 6, the flow value of each cement paste normalized to the flow value of the conventional cement mixture (Paste 1 in Table 1 ) is represented. The results obtained from the slump test show that the mixture 3 and 4 were more fluid than mixture 1 . The flow values decrease continuously for the DPET percentage greater than $20 \%$ (paste 4-5-6-7 in Table 1). 


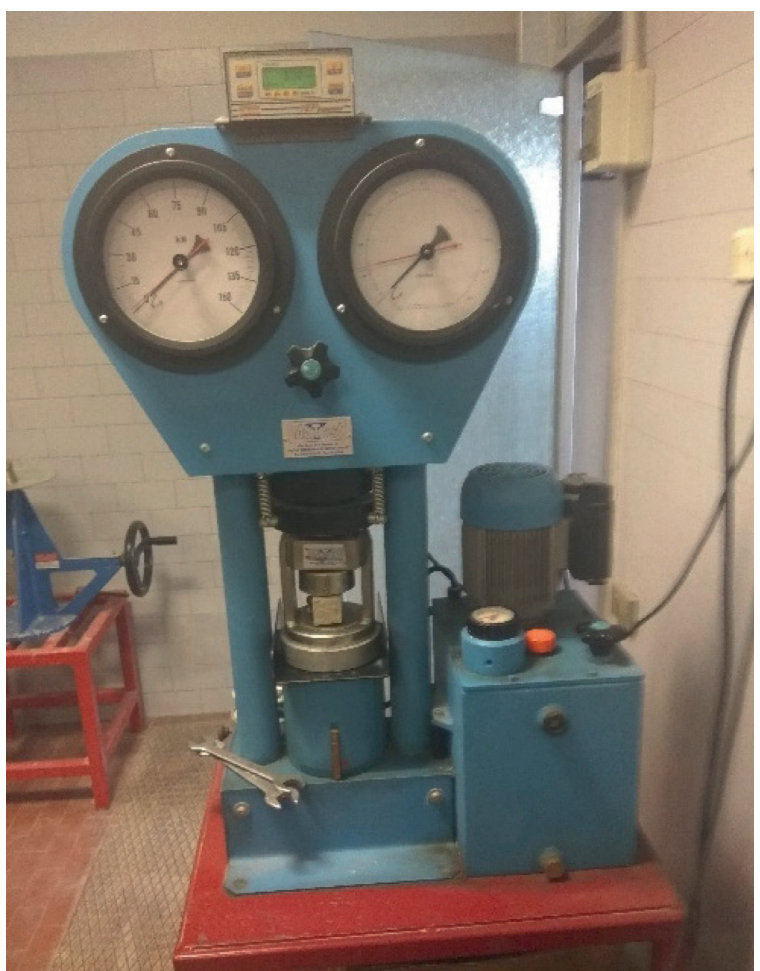

Figure 5: Compressive test on cubic sample.

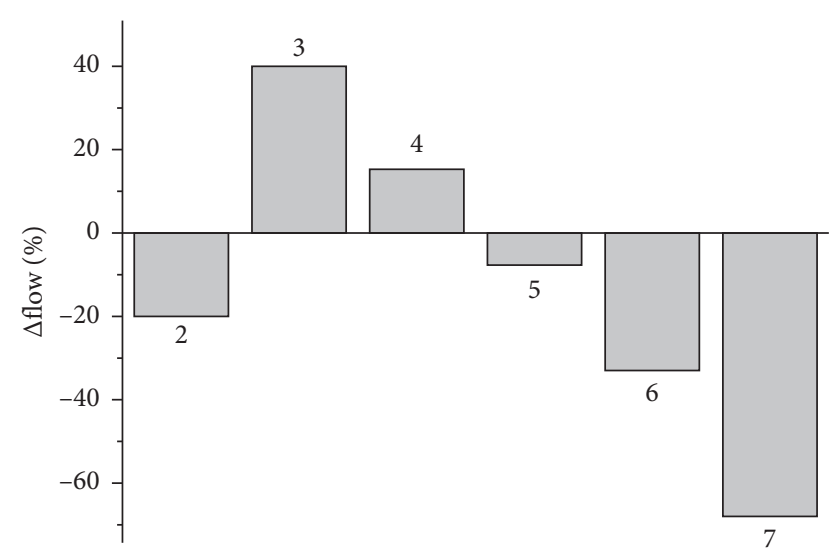

Figure 6: Flow values normalized to flow value of cement paste 1.

4.2. Thermal Conductivity. The results obtained from the thermal conductivity tests are reported in Table 3 and are represented in Figure 7(a). The thermal conductivity is substantially indicated as the attitude of a heat-transmitted material. The data relating to the conducted tests show that the experimental values regarding this characteristic decrease with the progressive increase of DPET amount in the cementitious paste.

In Table 3, the thermal diffusivity values of all tested specimens are reported. Such characteristic describes the propagation of the thermal field where the regime of the boundary conditions is not stationary and the capacity of the material to adapting to the changes in temperature imposed from the outside. Similarly to the thermal conductivity, the thermal diffusivity decreases when the DPET percentage increases in the mixture. This trend is not observed for sample 6, which can be still counted among the measurement errors due to the smaller surface of the test sensor.

It is clear from the results represented in Figure 7(b) that the more DPET is added to the mixture, the more the diffusivity is lowered, and therefore the thermal inertia increases.

The minimum thermal conductivity value was $0.35 \mathrm{~W} / \mathrm{m}$ $\mathrm{K}$, observed at $80 \%$ aggregates replacement. From this result, it was concluded that waste PET aggregates replacement with conventional aggregate in the mixture showed better insulation properties (i.e., lower thermal coefficient). The low unit weight and high thermal conductivity values of DPET mortars make it possible to assess the use of such materials in construction applications.

In fact, the thermal conductivity values of produced mortars decreased with increasing weight fractions of depolymerized plastic, and their thermal conductivities were lower than the ordinary mortar by about $31-62 \%$. Such reduction is in agreement with the experimental results in another preliminary research conducted on mortars with milled PET waste until reaching particles size similar to sand [36, 37]. In [37], the percentual improvement of thermal property has increased up to $57 \%$ in mortars with sand replacement by PET obtained by milling. As noted in the presented experimental results, the cement mortar containing a large part of polymeric material replacing sand preserves the high thermal performances of milled PET mortar with the added advantage of using nondepurated plastic waste. For this reason, it can prove to be a highly recommended material that can offer advantages in terms of thermal insulation.

4.3. Mechanical Strength. The flexural and compressive strengths of the different mixtures are collected in Table 4.

Specifically, Table 4 shows the variations in the flexural strength of the different mixtures as a function of the percentage of sand replaced by the same weight of plastic. Comparing with the control mixture, no significant changes are observed for mixtures containing up to $40 \%$ of DPET aggregates. However, a decrease of $46 \%$ and $51 \%$ for mixtures with, respectively, $60 \%$ and $80 \%$ of DPET content is observed. In Figure 8, the flexural strengths of the DPET mixture with respect to the specific weights are represented.

The experimental results show a decrease in compressive strength when the plastic content increases both the normalized and unnormalized sand mixtures. The drop in compressive strength seems not to be proportional to the weight fraction of sand replaced by plastic aggregates. In fact, a decrease of $20 \%$ for the mixture with $30 \%$ of DEPT aggregates and normalized sand (cement paste 2 in Table 4) is observed. For mixtures with, respectively, $20 \%, 40 \%, 60 \%$, and $80 \%$ of DPET aggregates and un normalized sand (cement paste 4, 5, 6, and 7 in Table 4) a decrease equal to $25 \%, 47 \%, 60 \%$, and $66 \%$ of compressive strength, respectively, is observed. The drop in compressive strengths due to the addition of plastic aggregates is closely related to the decrease of the specific weight of the DPET mixture (Figure 9). 
TABLE 3: Thermal conductivity and thermal diffusivity values of the seven mixtures investigated.

\begin{tabular}{lcccccc}
\hline $\begin{array}{l}\text { Cement } \\
\text { paste }\end{array}$ & Sand type & $\begin{array}{c}\text { Sand } \\
(\%)\end{array}$ & $\begin{array}{c}\text { DPET } \\
(\%)\end{array}$ & $\begin{array}{c}\text { Specific weight } \rho(\mathrm{kg} / \\
\left.\mathrm{m}^{3}\right)\end{array}$ & $\begin{array}{c}\text { Thermal conductivity }(\mathrm{W} / \\
\mathrm{mK})\end{array}$ & $\begin{array}{c}\text { Thermal diffusivity }\left(\mathrm{m}^{2} / \mathrm{s}\right) \mathrm{x} \\
10^{-8}\end{array}$ \\
\hline 1 & Normalized & 100 & - & 2100 & $2.02 \pm 0.05$ & $1.10 \pm 0.08$ \\
2 & Normalized & 70 & 30 & 1950 & $1.45 \pm 0.10$ & $0.892 \pm 0.05$ \\
3 & Unnormalized & 100 & - & 1960 & $0.99 \pm 0.06$ & $0.608 \pm 0.1$ \\
4 & Unnormalized & 80 & 20 & 1812 & $0.627 \pm 0.02$ & $0.426 \pm 0.03$ \\
5 & Unnormalized & 60 & 40 & 1636 & $0.57 \pm 0.02$ & $0.38 \pm 0.05$ \\
6 & Unnormalized & 40 & 60 & 1494 & $0.42 \pm 0.09$ & $0.518 \pm 0.06$ \\
7 & Unnormalized & 20 & 80 & 1451 & $0.35 \pm 0.01$ & $0.35 \pm 0.02$ \\
\hline
\end{tabular}

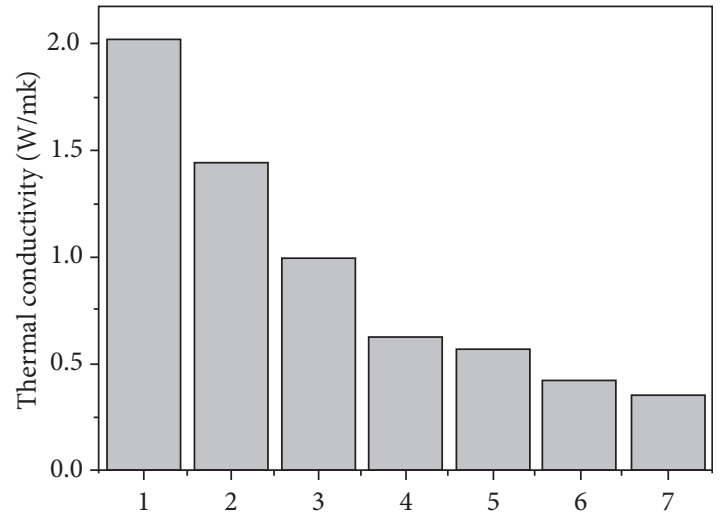

(a)

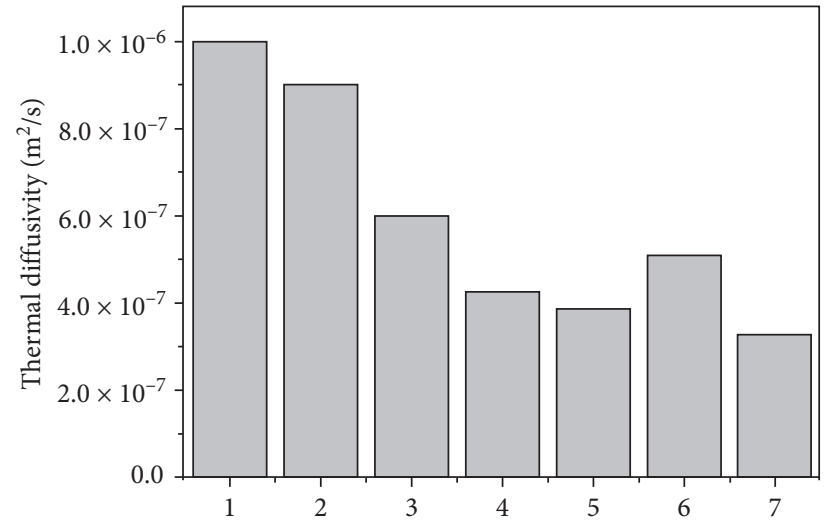

(b)

Figure 7: (a) Reduction of the thermal conductivity according to each mixture type; (b) reduction of the thermal diffusivity according to each mixture type.

TABLE 4: Results of flexural and compressive strength of cementitious pastes with different weight additions of DPET.

\begin{tabular}{lcccc}
\hline Cement paste & Sand type & DPET $(\%)$ & Flexural strength $R_{f}\left(\mathrm{~N} / \mathrm{mm}^{2}\right)$ & Compressive strength $R_{c}\left(\mathrm{~N} / \mathrm{mm}^{2}\right)$ \\
\hline 1 & Normalized & - & $10.02 \pm 0.53$ & $51.97 \pm 1.32$ \\
2 & Normalized & 30 & $8.80 \pm 0.25$ & $42.06 \pm 1.02$ \\
3 & Unnormalized & - & $6.87 \pm 0.48$ & $47.91 \pm 0.89$ \\
4 & Unnormalized & 20 & $7.79 \pm 0.50$ & $35.82 \pm 1.06$ \\
5 & Unnormalized & 40 & $6.77 \pm 0.47$ & $25.60 \pm 0.89$ \\
6 & Unnormalized & 60 & $4.36 \pm 0.31$ & $18.78 \pm 0.60$ \\
7 & Unnormalized & 80 & $3.32 \pm 0.32$ & $16.27 \pm 0.95$ \\
\hline
\end{tabular}

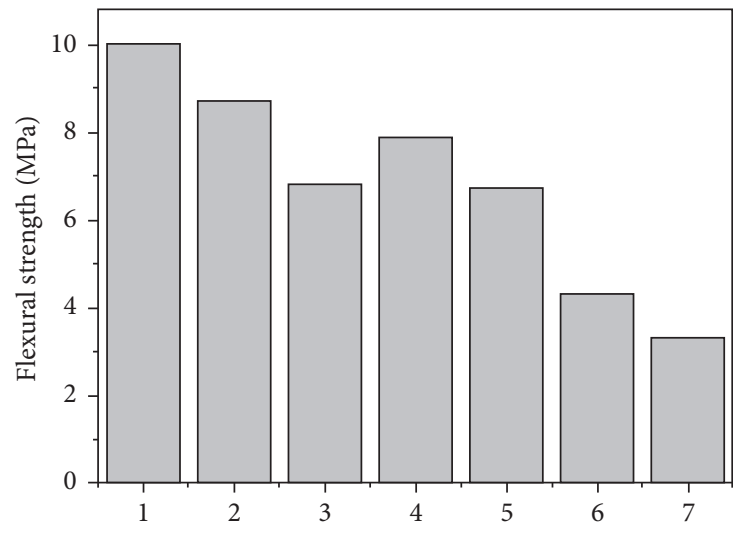

(a)

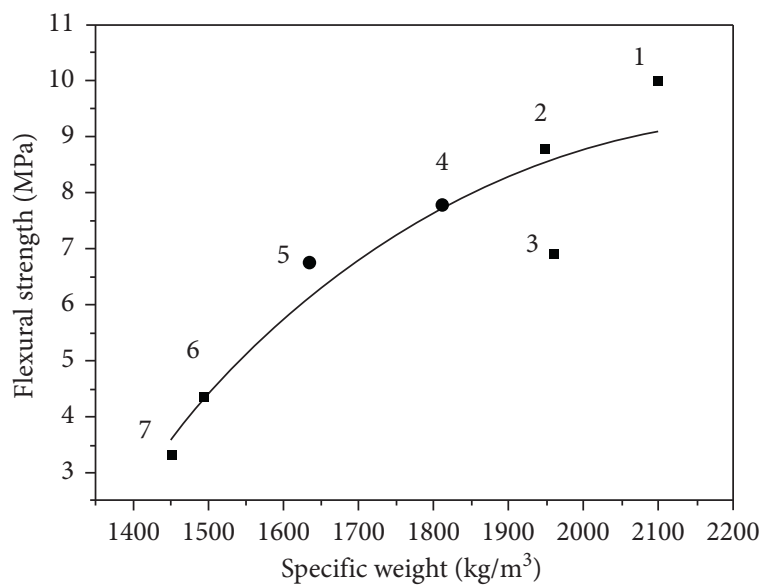

(b)

FIGURE 8: (a) Flexural strength according to tested mixture type; (b) relationship between the flexural strength and specific weight of the specimens. 


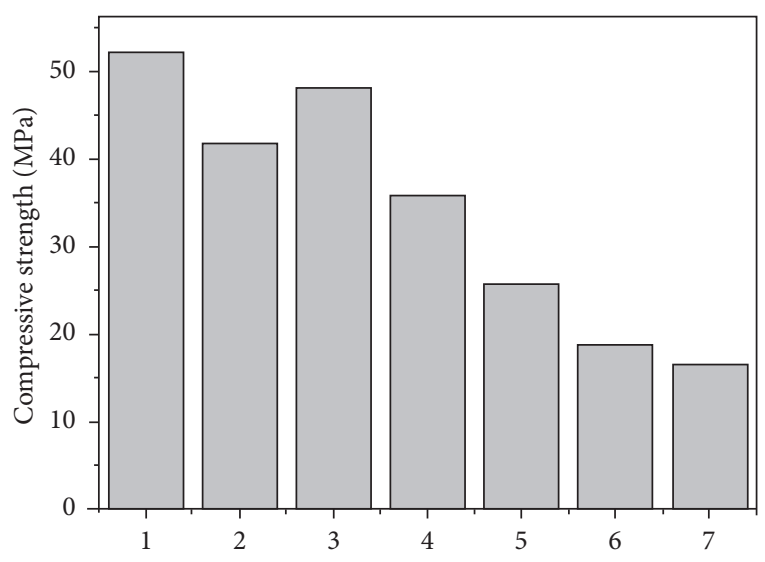

(a)

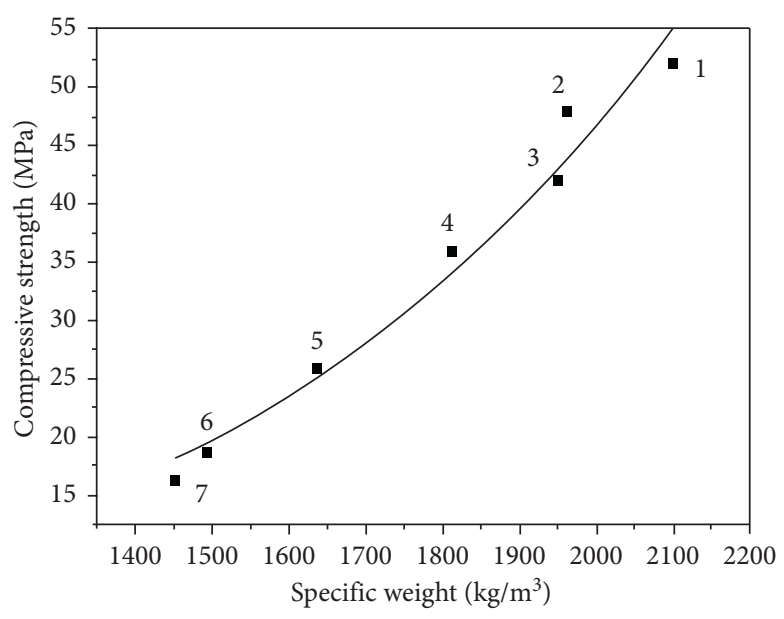

(b)

FIgURE 9: (a) Compressive strength according to tested mixture type; (b) relationship between the compressive strength and specific weight of the specimens.

The reduction of compressive and tensile strengths in correspondence of the increased proportion of the replaced aggregate results in agreement with the experimental evidence revealed by previous studies carried out on mortars containing milled PET particles [21, 22]. The mechanical behaviour DPETmortar results were comparable to mortars with the incorporation of ground PET waste. Depolymerization of the PET thus allows obtaining a mortar with similar performance without include the needed steps for the mechanical recycling on (i.e., separation based on shape, density or chemical composition of waste, and washing to removal of impurity).

\section{Conclusions}

In recent years, the recycling of PET has received a great deal of attention for the heavy amount of plastic material destinated to disposal treatment. The presented paper focused on the use of a postconsumer PET-bottles wastes as aggregates in a cement paste in order to evaluate its physical and mechanical characteristics. In the material research field, the postconsumer PET-bottles are mainly recycled into fibres through mechanical process. Nevertheless, mechanical processing can often lead to low-grade material due to the difficulty of obtaining fibres uniform throughout and free from defects. For this reason, the conducted research aimed to explore the possibility of using PET nanoparticles obtained by a chemical process as the depolymerization of plastic pieces through the glycolysis reaction using Ethylene Glycol as a solvent.

Different DPET percentages were added to the cement mixture in replacement of sand. The results of mechanical tests and thermal conductivity tests conducted on mortar mixed with chemically depolymerized PET have been compared with the performance of a traditional paste. The experimental data showed that the use of plastic nanoparticles decreases the mechanical performance in terms of flexural and compressive strength of the new mortars. The results showed that a higher percentage of DPET provides a lower heat-transfer capacity to the mortar. For this reason, the chemically DPET- mortars can be considered a valuable material in the building field for all those cases where a good thermal insulation level is required. Finally, the high advantage obtained from recycling a waste material like PET that is very dangerous for the environment must be underlined.

The present research on PET waste chemically recycle to improve mortar performance can be considered preliminary. It showed interesting properties of DPET mortars such as thermal conductivity; however, further study remains to optimize the chemical process conditions with several reagents and to define the optimal DPET-additive amount. Additionally, this research can also be expanded analysing the microstructure of DPET mortars and evaluating a possible fire resistance difference according to DPET utilization.

\section{Data Availability}

The data used to support the findings of the study are included in the article.

\section{Conflicts of Interest}

The authors declare that there are no conflicts of interest regarding the publication of this paper.

\section{References}

[1] S. Shahiron, "Concrete incorporated with optimum percentages of recycled polyethylene terephthalate (PET) bottle fiber," International Journal of Integrated Engineering, vol. 10, no. 1, 2018.

[2] M. Sulyman, J. Haponiuk, J. Haponiuk, and K. Formela, "Utilization of recycled polyethylene terephthalate (PET) in engineering materials: a review," International Journal of Environmental Science and Development, vol. 7, no. 2, p. 100, 2016.

[3] P. Sang Ho and K. Seong Hun, "Poly (ethylene terephthalate) recycling for high value added textiles," Fashion and Textiles, vol. 1, no. 1, pp. 1-17, 2014. 
[4] D. Foti, "Innovative techniques for concrete reinforcement with polymers," Construction and Building Materials, vol. 112, pp. 202-209, 2016.

[5] D. Foti and D. Cavallo, "Mechanical behavior of concretes made with non-conventional organic origin calcareous aggregates," Construction Build Mater, vol. 179, pp. 100-106, 2018.

[6] D. Foti, M. Lerna, M. Sabbà, and V. Vacca, "Mechanical characteristics and water absorption properties of blast-furnace slag concretes with fly ashes or microsilica additions," Applied Sciences, vol. 9, no. 7, p. 1279, 2019.

[7] D. Foti, "Preliminary analysis of concrete reinforced with waste bottles PET fibers," Construction and Building Materials, vol. 25, no. 4, pp. 1906-1915, 2011.

[8] L. A. Pereira de Oliveira and J. P. Castro-Gomes, "Physical and mechanical behaviour of recycled PET fibre reinforced mortar," Construction and Building Materials, vol. 25, no. 4, pp. 1712-1717, 2011.

[9] E. Silva, J. Coelho, and J. Bordado, "Hybrid polyethylene/ polypropylene blended fiber-reinforced cement composite," Journal of Composite Materials, vol. 47, no. 25, p. 3131, 2013.

[10] D. Foti, "Use of recycled waste pet bottles fibers for the reinforcement of concrete," Composite Structures, vol. 96, pp. 396-404, 2013.

[11] T. Ochi, S. Okubo, and K. Fukui, "Development of recycled PET fiber and its application as concrete-reinforcing fiber," Cement and Concrete Composites, vol. 29, no. 6, pp. 448-455, 2007.

[12] D. Foti and F. Paparella, "Impact behavior of structural elements in concrete reinforced with PET grids," Mechanics Research Communications, vol. 57, pp. 57-66, 2014.

[13] D. A. Silva, A. M. Betioli, P. J. P. Gleize, H. R. Roman, L. A. Gómez, and J. L. D. Ribeiro, "Degradation of recycled PET fibers in Portland cement-based materials," Cement Concr. Res.vol. 35, pp. 1741-1746, 2004.

[14] S. De Silva and T. Prasanthan, "Application of recycled PET fibers for concrete floors," Engineer: Journal of the Institution of Engineers, Sri Lanka, vol. 52, no. 1, pp. 21-27, 2019.

[15] B. Yesilata, Y. Isıker, and P. Turgut, "Thermal insulation enhancement in concretes by adding waste PET and rubber pieces," Construction and Building Materials, vol. 23, no. 5, pp. 1878-1882, 2009.

[16] K. Ragaert, L. Delva, and K. Van Geem, "Mechanical and chemical recycling of solid plastic waste," Waste Management, vol. 69, pp. 24-58, 2017.

[17] Z. Guo, K. Lindqvist, and H. de la Motte, "An efficient recycling process of glycolysis of PET in the presence of a sustainable nanocatalyst," Journal of Applied Polymer Science, vol. 135, no. 21, p. 46285, 2018.

[18] Y.-W. Choi, D.-J. Moon, J.-S. Chung, and S.-K. Cho, "Effects of waste PET bottles aggregate on the properties of concrete," Cement and Concrete Research, vol. 35, no. 4, pp. 776-781, 2005.

[19] O. Y. Marzouk, R. M. Dheilly, and M. Queneudec, "Valorization of post-consumer waste plastic in cementitious concrete composites," Waste Management, vol. 27, no. 2, pp. 310-318, 2007.

[20] M. Frigione, "Recycling of PET bottles as fine aggregate in concrete," Waste Management, vol. 30, no. 6, pp. 1101-1106, 2010.

[21] K. Hannawi, S. Kamali-Bernard, and W. Prince, "Physical and mechanical properties of mortars containing PET and PC waste aggregates," Waste Management, vol. 30, no. 11, pp. 2312-2320, 2010.
[22] E. Rahmani, M. Dehestani, M. H. A. Beygi, H. Allahyari, and I. M. Nikbin, "On the mechanical properties of concrete containing waste PET particles," Construction and Building Materials, vol. 47, pp. 1302-1308, 2013.

[23] L. Ávila Córdoba, G. Martínez-Barrera, C. Barrera Díaz, F. Ureña Nuñez, and A. Loza Yañez, "Effects on mechanical properties of recycled PET in cement-based composites," International Journal of Polymer Science, vol. 2013, pp. 1-6, Article ID 763276, 2013.

[24] F. Mahdi, H. Abbas, and A. A. Khan, "Strength characteristics of polymer mortar and concrete using different compositions of resins derived from post-consumer PET bottles," Construction and Building Materials, vol. 24, no. 1, pp. 25-36, 2010.

[25] F. Mahdi, H. Abbas, and A. A. Khan, "Flexural, shear and bond strength of polymer concrete utilizing recycled resin obtained from post consumer PET bottles," Construction and Building Materials, vol. 44, pp. 798-811, 2013.

[26] S. Nica, A. Hanganu, A. Tanase et al., "Glycolytic depolymerization of polyethylene terephtalate (PET) wastes," Revista de Chimie Bucharest, vol. 66, no. 8, pp. 1105-1111, 2015.

[27] A. M. Al-Sabagh, F. Z. Yehia, G. Eshaq, A. M. Rabie, and A. E. ElMetwally, "Greener routes for recycling of polyethylene terephthalate," Egyptian Journal of Petroleum, vol. 25, no. 1, pp. 53-64, 2016.

[28] S. M. Cakić, I. S. Ristić, M. M. Cincović, N. Č. Nikolić, L. B. Nikolić, and M. J. Cvetinov, "Synthesis and properties biobased waterborne polyurethanes from glycolysis product of PET waste and poly (caprolactone) diol," Progress in Organic Coatings, vol. 105, pp. 111-122, 2017.

[29] R. López-Fonseca, I. Duque-Ingunza, B. De Rivas, S. Arnaiz, and J. I. Gutiérrez-Ortiz, "Chemical recycling of post-consumer PET wastes by glycolysis in the presence of metal salts," Polymer Degradation and Stability, vol. 95, no. 6, pp. 1022-1028, 2010.

[30] M. Zhu, S. Li, Z. Li, X. Lu, and S. Zhang, "Investigation of solid catalysts for glycolysis of polyethylene terephthalate," Chemical Engineering Journal, vol. 185-186, pp. 168-177, 2012.

[31] J. R. Campanelli, M. R. Kamal, and D. G. Cooper, "Kinetics of glycolysis of poly(ethylene terephthalate) melts," Journal of Applied Polymer Science, vol. 54, no. 11, pp. 1731-1740, 1994.

[32] M. Alzuhairi, A. Al-Ghaban, and S. Almutalabi, "Chemical recycling of polyethylene terephthalate (waste water bottles) for improving the properties of asphalt mixture," in Proceedings of the MATEC Web of Conferences, vol. 162, EDP Sciences, Bandung, Indonesia, April 2018.

[33] J.-W. Chen, L.-W. Chen, and W.-H. Cheng, "Kinetics of glycolysis of polyethylene terephthalate with zinc catalyst," Polymer International, vol. 48, no. 9, pp. 885-888, 1999.

[34] M. A. H. Alzuhairi, A. M. Al-Ghaban, and S. N. Almutalabi, "Chemical recycling of Polyethylene Terephthalate (PET) as additive for asphalt," ZANCO Journal of Pure and Applied Sciences, vol. 28, no. 2, pp. 675-679, 2016.

[35] EN, TS. 196-1, Methods of Testing Cement-Part 1: Determination of Strength, Vol. 26, European Committee for standardization, Brussels, Belgium, 2005.

[36] A. S. Benosman, M. Mouli, H. Taibi et al., "Chemical, mechanical and thermal properties of mortar composites containing waste pet," Environmental Engineering and Management Journal, vol. 16, no. 7, pp. 1489-1505, 2017.

[37] M. R. Oliveira, M. da Luz Garcia, A. C. M. Castro, and T. N. Silva, "Mortar with pet-preliminary results," Energy Reports, vol. 6, pp. 800-803, 2020. 